\title{
BMJ Parenteral Pethidine for labour pain Open relief and substance use disorder: 20-year follow-up cohort study in offspring
}

\author{
Robert Rodrigues Pereira, ${ }^{1,2,3}$ Humphrey Kanhai, ${ }^{4}$ Frits Rosendaal, ${ }^{5}$ \\ Paula van Dommelen, ${ }^{6}$ Dick Swaab, ${ }^{7}$ Erik Rodrigues Pereira, ${ }^{8}$ \\ Ben van de Wetering ${ }^{9}$
}

To cite: Rodrigues Pereira R, Kanhai $\mathrm{H}$, Rosendaal F, et al. Parenteral Pethidine for labour pain relief and substance use disorder: 20-year follow-up cohort study in offspring. BMJ Open 2012;2:e000719. doi:10. 1136/bmjopen-2011-000719

- Prepublication history for this paper is available online. To view these files please visit the journal online (http:// dx.doi.org/10.1136/ bmjopen-2011-000719).

Received 5 December 2011 Accepted 1 May 2012

This final article is available for use under the terms of the Creative Commons Attribution Non-Commercial

2.0 Licence; see

http://bmjopen.bmj.com

For numbered affiliations see end of article.

Correspondence to

Dr Robert Rodrigues Pereira; pereirar@

maasstadziekenhuis.nl

\section{ABSTRACT}

Objective: To determine whether use of intrapartum Pethidine pain analgesia increases the risk for substance use disorder in adult offspring.

Design: Analysis of data from a cohort study.

Setting: Academic hospital in Leiden, the Netherlands Participants: 133 cases and 164 control individuals, aged 18-20 years at follow-up.

Main outcome measure: Incidence of substance use disorder or use of alcohol and tobacco.

Results: The lifetime use of addictive substances in children exposed to intrapartum Pethidine analgesia was $45 \%$ of 133 children versus $48 \%$ of 164 notexposed subjects (adjusted $\mathrm{OR}=0.79,95 \% \mathrm{Cl} 0.48$ to 1.29). Recent use of alcohol, tobacco and hard drugs showed no statistical difference either.

Conclusion: Pethidine for labour pain medication appears not to be associated with substance misuse or smoking in later life.

\section{INTRODUCTION}

Analgesia during labour is common worldwide. Methods used include barbiturates, nitrous oxide, opioids, epidural analgesia, transcutaneous electric nerve stimulation, psychoprophylaxis and hypnosis. In the Netherlands, opiates had been used in $7 \%-$ $15 \%$ of all deliveries between 2000 and 2007, which is in 15000-30000 mothers a year. ${ }^{1}$ In the 1970 s, intramuscular Pethidine ${ }^{\circledR}$ was the most common drug for pain relief during labour. In recent years, a rise in the use of epidural or spinal analgesia and in PCA (patient-controlled analgesia) with very short acting opiates intravenously is observed. However, Pethidine ${ }^{\circledR}$ is the most commonly used opioid worldwide because it is cheap and easy to administer. Concerns have been raised about its effectiveness and potential maternal, fetal and neonatal side effects. ${ }^{2}$

\section{ARTICLE SUMMARY}

Article focus

- Research question: does perinatal Pethidine for labour pain relief lead to substance use disorder in later life?

- Is it possible to confirm the published data on an OR of around 5 ?

- We hypothesise that there is no relationship.

Key messages

- We cannot confirm earlier data on the risk of substance use disorder after perinatal analgesia.

- We did not find a risk for smoking and drinking alcohol either.

- Perinatal Pethidine analgesia appears not to be associated with substance misuse in later life.

Strengths and limitations of this study

- This is a well-designed large cohort study on long-term effects of perinatal Pethidine analgesia.

- The main limitation is the relatively low response and the possible selective response.

After parenteral therapy in the mother, the opiates can be detected in cord blood with a plasma level of $50 \%$ of that of the mother. After birth, the child is often sleepy and slightly respiratory depressed for a few hours. ${ }^{3} 4$

In 1987, the issue of development of substance use disorders (SUDs) and behavioural problems in the offspring after perinatal analgesic medication was addressed. ${ }^{5}$ The authors reported ORs of 4.7 compared with individuals who did not receive perinatal analgesic drugs. These results were derived from case-control studies in patients with SUD. ${ }^{6-8}$

The SUD was attributed to the 'imprinting hypothesis' and was first published in the BMJ in 1990 by Jacobson et al. ${ }^{7}$ The brain, when exposed to a noxe during a window in time before or during birth, could be 
affected permanently by changing neurotransmitter receptors, synaptogenesis, myelination, proliferation, apoptosis, migration of neuronal cells or by stunting of dendrite growth. ${ }^{9-12}$ An epidemiological and clinical study showed that cannabis exposure before birth is associated with impulsive and psychiatric disorders in later life. ${ }^{13}$ Conflicting results have been publishes about the association of autism spectrum disorders, developmental delay and learning disorders in offspring after peripartum exposure to analgesics. ${ }^{14-17}$

No long-term follow-up study in children born after opioid use of the mother during pregnancy or after opioid labour analgesia has been published. A recent Cochrane Review has been published looking at the effectiveness and side effects of intrapartum parenteral opioids. ${ }^{18}$ Short-term follow-up studies did not show sequelae in children in their development up to 5 years. ${ }^{19-22}$

We investigated the association between Pethidine ${ }^{\circledR}$ use and the risk on smoking, drinking alcohol or drug abuse in offspring 20 years after birth.

\section{METHODS}

\section{Sample and study design}

Power calculation

Considering the prevalence of drug abuse, smoking and drinking alcohol, we needed 160 participants in each group. In total, 85 individuals in each group were sufficient to detect an OR of 4.7 or more between the groups with $80 \%$ power and a type I error of $0.05,{ }^{7}$ assuming a prevalence of major drug abuse in the control group of $5 \% .{ }^{1}$ Because of the much more frequent use of tobacco and alcohol, this sample size was sufficient to detect ORs around two.

Data about lifetime prevalence and recent substance use are available for Europe ${ }^{23}$ and for the Netherlands ${ }^{24}$ (table 1).

\section{Identification of the cohort variables}

After ethical approval by the Medical Ethical Committee of the Leiden University Medical Center, the birth files from the Academic Hospital Leiden from 1986 to 1987 were used to compose two groups of participants: one cohort with and the other without labour analgesia by Pethidine ${ }^{\circledR}$. Included were only healthy babies without

Table 1 Lifetime prevalence and recent tobacco, alcohol and drug use in the Netherlands ${ }^{24}$

\begin{tabular}{ll}
$\begin{array}{l}\text { Lifetime } \\
\text { prevalence (\%) }\end{array}$ & $\begin{array}{l}\text { Recent use, } \\
\text { last month (\%) }\end{array}$ \\
\hline 72 & 37 \\
90 & 79 \\
37 & 17 \\
6.2 & 2.2 \\
5 & 1.9 \\
4.3 & 1.7 \\
\hline
\end{tabular}

congenital anomalies, born at term after an uncomplicated delivery and who had not been admitted in the paediatric ward. Information was available on maternal characteristics and obstetric history including medication as well as the postpartum condition of the newborn.

\section{Data collection}

After finding the recent addresses, we were able to send validated questionnaires about lifetime and recent (last month) use of cigarettes, alcohol and drugs. The first is the National Drugs Questionnaire as a part of the Permanent National Life Style Inquiry that is used from 1997 (with computer-assisted personal interviewing or in case of drug questions with computer-assisted self-interviewing method) that meet with the European Statistics Code of Practice. The second questionnaire is a validated questionnaire for young adults about life events, schooling and behaviour. ${ }^{25}$

\section{Analysis}

The primary analysis was a comparison of the prevalence of substance abuse at adult age between the Pethidine ${ }^{\circledR}$ exposed and not-exposed groups. Subsequently, the results were compared with the national drug monitor study that was done in the same period. A multivariate logistic regression model was used to calculate ORs and 95\% CIs for the outcome measures with age, sex, religion and parental education as potential confounders. The analyses were performed with SPSS V.11.5 for Windows (SPSS Inc).

\section{Non-response}

Non-responders received a short questionnaire about yes or no lifetime or recent use of alcohol, smoking and drugs. The individuals who responded to the short questionnaire and those who only partially filled in the questionnaire were analysed separately.

\section{RESULTS}

From a total of 715 deliveries, $91 \%$ of the addresses were found. Of these 651 individuals, $347(53 \%)$ returned the questionnaires. One hundred and thirty-three participants with and 164 without Pethidine ${ }^{\circledR}$ analgesia could be fully evaluated $(n=297,46 \%)$. After a second call, 26 individuals with and 24 without Pethidine ${ }^{\circledR}$ analgesia completed the questionnaire and 92 (53 with and 39 without Pethidine $\left.{ }^{\circledR}\right)$ completed the short questionnaire.

All together, 439 children (67\% of 651 children) were analysed. Both the index and the control group showed the same distribution of age and sex. There were no differences in the distribution of parental education or religion (table 2). These were also similar to national data. The peripartum data of both groups showed no differences in birth weight, sex and Apgar scores. All newborns were healthy and none was admitted in the paediatric ward.

No differences were found in lifetime or recent use of drugs, alcohol or tobacco use between both groups. The 
Table 2 Distribution of parental education or religion stratified by Pethidine $\AA$ and no Pethidine $\AA$ groups

\begin{tabular}{|c|c|c|c|}
\hline & $\begin{array}{l}\text { Total group } \\
(n=297)\end{array}$ & $\begin{array}{l}\% \text { Pethidine } \AA \\
(n=133)\end{array}$ & $\begin{array}{l}\% \text { No } \\
\text { Pethidine } \AA \\
(n=164)\end{array}$ \\
\hline \multicolumn{4}{|l|}{ Religion } \\
\hline Christian & 41.4 & 39.8 & 42.7 \\
\hline Other & 4.4 & 6.8 & 2.4 \\
\hline No & 54.2 & 53.4 & 54.9 \\
\hline \multicolumn{4}{|l|}{ Education } \\
\hline Low & 38.4 & 32.3 & 43.3 \\
\hline Intermediate & 27.9 & 32.3 & 24.4 \\
\hline High & 33.7 & 35.3 & 32.3 \\
\hline \multicolumn{4}{|l|}{ Sex } \\
\hline Male & 39.4 & 42.1 & 37.2 \\
\hline Female & 60.6 & 57.9 & 62.8 \\
\hline
\end{tabular}

OR for ever drug abuse was 0.79 (95\% CI 0.48 to 1.29 ) and for recent drug abuse 1.08 (95\% CI 0.49 to 2.37). We also gathered data about alcohol use, cannabis and smoking during and after secondary school. These data did not show differences between the groups either, the adjusted ORs are presented in table 3. In total, 92 children responded to the short questionnaire and 50 children partially filled out the standard questionnaire. No difference was found in lifetime prevalence of smoking, alcohol and drug abuse between the Pethidine ${ }^{\circledR}$ and the non-Pethidine ${ }^{\circledR}$ group independent of the dose that ranged from 75 to $150 \mathrm{mg}$. The ORs were all close to unity, varying between 0.58 and 1.42 .

\section{DISCUSSION}

This 20-year follow-up study showed that labour analgesia by Pethidine ${ }^{\circledR}$ did not significantly increase the risk of SUD in offspring. We found no association for hard drugs, tranquilisers, hallucinogenics, anabolics or soft drugs (including tobacco and alcohol use). This is in line with the results of the study from the Mayo clinics on the risk of learning disability after exposure to peripartum analgesia. ${ }^{14}$

The strength of this study is that it is a large, long-term follow-up study of a healthy cohort of neonates.

We evaluated putative confounders, such as socioeconomic status, sex, religion and parental education, but did not find differences between the index and the control group. Uncontrolled confounding is always possible, but in this instance, one would expect these to lead to spurious positive associations and not to the absence of an association. Further investigation of potential confounders could be valuable. Given the result of the previous studies reporting a fivefold increased risk, our sample size with a minimal detectable RR of 2 was conservative. However, this implies that we could not detect small risk increases. Nevertheless, the most likely interpretation of our findings, which exclude a risk increase of more than $29 \%$ of lifetime drug abuse in children exposed to Pethidine, is the absence of any association.

The main limitation of the study is the low response and the possibility of selected response. It is not inconceivable that drug users responded less than others. It is of some concern that response was lower in the group exposed during labour $(54 \%)$ than in those who were not $(42 \%)$. Still, if selective response was only associated to drug use in adult life, one would expect an attenuated effect but not the absence of any effect. Bias would have resulted from a differential response related to opioid use during delivery, irrespective of drug use later in life. This seems implausible, as most young adults will not be aware of the analgetic medication of their mothers during birth. Reassuring for the absence of major bias is the fact that the non-respondents to the first questionnaire, who responded to the second short questionnaire

Table 3 Lifetime or recent use of alcohol, tobacco and drugs stratified by Pethidine $\AA$ and no Pethidine $\AA$ groups

\begin{tabular}{|c|c|c|c|c|}
\hline & $\begin{array}{l}\text { Total group } \\
(n=297)\end{array}$ & $\begin{array}{l}\% \text { Pethidine } \AA \\
(n=133)\end{array}$ & $\begin{array}{l}\% \text { No Pethidine } \AA \\
(n=164)\end{array}$ & Adjusted OR $(95 \% \mathrm{Cl})^{\star}$ \\
\hline Smoking cigarettes ever & 70.4 & 68.4 & 72.0 & $0.84(0.50$ to 1.41$)$ \\
\hline Smoking cigarettes recent & 41.4 & 40.6 & 41.5 & $0.98(0.61$ to 1.58$)$ \\
\hline Alcohol ever & 98.7 & 98.5 & 98.8 & $0.81(0.10$ to 6.23$)$ \\
\hline Alcohol recent & 86.5 & 86.5 & 86.6 & $0.91(0.45$ to 1.81$)$ \\
\hline Smoking cannabis ever & 46.5 & 45.1 & 47.6 & $0.76(0.46$ to 1.24$)$ \\
\hline Smoking cannabis recent & 8.8 & 9.8 & 7.9 & $1.14(0.50$ to 2.63$)$ \\
\hline XTC ever & 10.1 & 12.0 & 8.5 & $1.42(0.64$ to 3.17$)$ \\
\hline XTC recent & 1.0 & 2.3 & 0 & - \\
\hline Amphetamine ever & 5.4 & 4.5 & 6.1 & $0.66(0.22$ to 1.99$)$ \\
\hline Amphetamine recent & 1.0 & 0.8 & 1.2 & 0.58 (0.05 to 6.61$)$ \\
\hline Cocaine ever & 6.4 & 6.0 & 6.7 & 0.85 (0.32 to 2.29$)$ \\
\hline Cocaine recent & 2.7 & 2.3 & 3.0 & $0.58(0.12$ to 2.68$)$ \\
\hline Drug abuse $\dagger$ ever & 46.8 & 45.9 & 47.6 & 0.79 (0.48 to 1.29$)$ \\
\hline Drug abuse $†$ recent & 10.1 & 10.5 & 9.8 & 1.08 (0.49 to 2.37$)$ \\
\hline
\end{tabular}


showed the same negative association for SUD, drinking and smoking. The non-responders showed an unequal distribution in sex compared with the responders: $41 \%$ vs $59 \%$ male/female ratio.

In this large follow-up study, we cannot confirm the results of previous studies that parenteral Pethidine ${ }^{\circledR}$ for labour pain relief is associated with SUD in later life. Because of the above-mentioned limitations, further research is needed to assess possible associations between other forms of intrapartum analgesia and SUD.

\section{Author affiliations}

${ }^{1}$ Department of Paediatrics, Maasstadziekenhuis, Rotterdam, the Netherlands

${ }^{2}$ Bouman Mental Health Care, Rotterdam, the Netherlands

${ }^{3}$ Department of Prevention and Care Netherlands Institute of Applied Sciences TNO, Leiden, the Netherlands

${ }^{4}$ Department of Obstetrics, Leiden University Medical Center, Leiden, the Netherlands

${ }^{5}$ Department of Clinical Epidemiology, Leiden University Medical Center, Leiden, the Netherlands

${ }^{6}$ Department of statistics, Netherlands Institute of Applied Sciences TNO, Leiden, the Netherlands

${ }^{7}$ Netherlands Institute for Neuroscience, an Institute of the KNAW, Amsterdam, the Netherlands

${ }^{8}$ Central Office for Motor Vehicle Driving Testing (CBR), Amsterdam, the Netherlands

${ }^{9}$ Bouman Mental Health Care, Rotterdam, the Netherlands

Contributors All authors contributed to the following criteria: (1) substantial contribution to conception and design, acquisition of data or analysis and interpretation of data; (2) drafting the article or revising it critically for important intellectual content and (3) final approval of the version to be published.

Funding This research received no specific grant from any funding agency in public, commercial or not-for-profit sectors.

Competing interests None.

Patient consent Obtained.

Ethics approval Ethics approval was provided by Medical Ethical Committee of the Leiden University Medical Center, the Netherlands.

Provenance and peer review Not commissioned; externally peer reviewed.

Data sharing statement All data are uploaded to the Dryad data repository and available for any scientist.

\section{REFERENCES}

1. The Netherlands Perinatal Registry. http://www.perinatreg.nl/ home english

2. Bricker L, Lavender T. Parenteral opioids for labour pain relief: a systematic review. Am J Obstet Gynecol 2002;186(5 Suppl Nature): S94-109.
3. Thomas $\mathrm{H}$, Asskali $\mathrm{F}$, Vettermann J. Addition of fentanyl to bupivacaine-peridural analgesia in cesarian section. Anaesthesist 1996;45:635-42.

4. Nicolle E, Devillier P, Durand C, et al. Therapeutic monitoring of nalbuphine: transplacental transfer and estimated pharmacokinetics in the neonate. Eur J Clin Pharmacol 1996;49:485-9.

5. Jacobson B, Eklund G, Hamberger L, et al. Perinatal origin of adult self-destructing behaviour. Acta Psychiatr Scand 1987;76:364-71.

6. Jacobson B, Nyberg K, Eklund G, et al. Obstetric pain medication and eventual adult amphetamine addiction in offspring. Acta Obstet Gynecol Scand 1988;67:677-82.

7. Jacobson B, Nyberg K, Grönbladh L, et al. Opiate addiction in adult offspring through possible imprinting after obstetric treatment. BMJ 1990;30:1067-70.

8. Nyberg K, Buka S, Lipsitt LP. Perinatal medication as a potential risk factor for adult abuse in a North American cohort. Epidemiology 2000;11:715-16.

9. Tchernitchin AN, Tchernitchin NN, Mena MA, et al. Imprinting: perinatal exposures cause the development of diseases during the adult age. Acta Biol Hung 1999;50:425-40.

10. Fernanadez-Ruiz J, Berrendero F, Hernández ML, et al. The endogenous cannabinoid system and brain development. Trends Neurosci 2000;23:14-20.

11. Swaab DF, Boer K, Mirmian M. Functional teratogenic effects of chemicals on the developing brain. In: Levene MI, Chervenak FA eds. Fetal and Neonatal Neurology and Neurosurgery. Toronto: Churchill Livingstone, 2001:263-77.

12. Ricalde A, Hammer RP. Perinatal opiate treatment delays growth of cortical dendrites. Neurosci Lett 1990;115:137-43.

13. Spano MS, Ellgren M, Wang $X$, et al. Prenatal cannabis exposure increases heroin seeking with allostatic changes in limbic enkefalin systems in adulthood. Biol Psychiatry 2007;61:554-63.

14. Flick RP, Lee K, Hofer RE, et al. Neuraxial labor analgesia for vagina delivery and its effect on childhood learning disabilities. Anaesth Analg 2011;112:1424-31.

15. Hattori R, Desimaru M, Nagayami I, et al. Autistic and developmental disorders after general anesthetic delivery. Lancet 1991;337:1357-8

16. Sun LS. Editorial: labor analgesia and the developing human brain Aneasth Analg 2011;112:1265-7.

17. Wong CA, Scavone BM, Peaceman AM, et al. The risk of caesarean delivery with neuraxial analgesia given early versus late in labor. $N$ Engl J Med 2005;352:655-65

18. Ullman R, Smith LA, Burns $\mathrm{E}$, et al. Parenteral opioids for maternal pain management in labour. Cochrane Database Syst Revi 2010;(9): CD007396.

19. Kaye K, Elkind L, Goldberg D, et al. Birth outcomes for infants of drug abusing mothers. N Y State J Med 1989;89:256-61.

20. Doberczak TM, Kandall SR, Friedmann P. Relationship between maternal methadone dosage, maternal-neonatal methadone levels, and neonatal withdrawal. Obstet Gynecol 1993;81:936-40.

21. Hagopian GS, Wolfe HM, Sokol RJ, et al. Neonatal outcome following methadone exposure in utero. J Matern Fetal Med 1996;5:348-54

22. Thaithumyanon $\mathrm{P}$, Limpongsanurak $\mathrm{S}$, Praisuwanna $\mathrm{P}$, et al. Perinatal effects of amphetamine and heroin use during pregnancy on the mother and infant. J Med Assoc Thai 2007;88:1506-13.

23. Jaarverslag over de stand van de drugsproblematiek in de Europese Unie. Lisbon: E.W.D.D, 2000. ISBN 92-9168-100-8.

24. Trimbos-instituut, Jeugd en riskant gedrag, kerngegevens 1999 , Utrecht: Cf international equivalent, 2000. http://www.espad.org/ espad-reports

25. Stam H, Grootenhuis MA, Last BF. The course of life of survivors of childhood cancer. Psychooncology 2005;14:227-38. 